\title{
An international perspective for' Improving teacher professional development for online and blended learning: a systematic meta-aggregative review'
}

\author{
Javier Portillo ${ }^{1}$ D $\cdot$ Arantzazu Lopez de la Serna ${ }^{1}$ (D)
}

Accepted: 22 October 2020 / Published online: 4 November 2020

(c) Association for Educational Communications and Technology 2020

\begin{abstract}
This paper is in response, from an international perspective, to the manuscript entitled "Improving teacher professional development for online and blended learning: a systematic meta-aggregative review" (Philipsen, B., Tondeur, J., Pareja Roblin, N. et al. 2019).

The impact of the manuscript has been reinforced by the claims of international organisations like UNESCO and ILO, as far as they highlight that Teacher Professional Development (TPD) for Online and Blended Learning are a priority in the present scenario. The findings can be clearly applied to guide appropriated TPD for the recovery as well as for a resilient education system. Nevertheless, the research was conducted in a West-European context where most learners use computers on an everyday basis, while half the world's students do not have access to a household computer, and this has determined the emergency response to the pandemic. Dreesen et al. (2020) reported that most of the countries have adopted a remote education based on some combination of digital platforms, television, radio, take-home packages, home visits, text messaging and phone calls. It would be very interesting to incorporate these recent discoveries in the use of frugal technologies and elucidate if new components should be aggregated for TPD strategies from an international perspective. As far as the authors adopted the approach of a systematic meta-aggregative review, new data supported by unequivocal or credible evidence can be conveniently incorporated without reinterpreting the original findings.
\end{abstract}

Keywords Online learning · Blended learning · Teacher professional development

Javier Portillo

javier.portillo@ehu.eus

Arantzazu Lopez de la Serna

arantzazu.lopez@ehu.eus

1 University of the Basque Country, Leioa, Spain 


\section{Response article}

UNESCO (2020a) reported that the pandemic reached a peak in April and has affected 1,6 billion learners (91.3\% of total enrolled learners) and has caused widespread school closures in 194 countries. The emergency response to this global disruption has been an abrupt and unplanned shift to digital and distance learning. The next huge international challenges that education faces are recovery in the short term and building resilient education systems for the future. UNESCO and ILO (2020) claim TPD (Teacher Professional Development) for OBL (Online and Blended Learning) is a priority in both scenarios.

The article we are discussing was created for guiding practitioners, policy makers and researchers in their decision making regarding TPD. The article summarizes, as the result of a systematic literature review, the most important six components of TPD strategies on how to teach in OBL environments: (1) Design and develop a supportive TPD programme and environment for OBL, (2) Acknowledge the existing context regarding OBL, (3) Address teacher change associated with the transition to OBL, (4) Determine the overall goals and relevance of TPD for OBL, (5) Acknowledge TPD strategies associated with the transition to OBL and (6) Disseminate knowledge, skills, and attitudes about OBL and evaluate the TPD. Each of the components is described in terms of 'main categories' and 'action recommendations'.

The research was conducted in a West-European context, where a majority of learners use computers, and this is an overall limitation from an international perspective. Unfortunately, half the world's students (826 million) do not have access to a household computer and 706 million students lack internet access (UNESCO, 2020b). Dreesen et al. (2020) report that $68 \%$ of countries have responded to the lockdown situation with some combination of digital and non-digital delivery of remote education: Digital (73\%), television (75\%), radio (58\%), take-home packages (48\%), home visit (7\%). Some of these channels are one-directional but gathering of feedback from parents and caregivers is essential for monitoring, consequently simple tools like SMS, chatbots and messaging apps have served for comeback information. So-called frugal technology has proven to be very useful worldwide (UNESCO, 2020c) in a disruptive situation with little time to react, limited resources and teachers inexperienced with online learning. The variety of contexts is so wide -having or not electricity, radio, TV, mobile phone, internet connection or computer- that a remote learning decision tree (UNICEF, 2020) has been developed, a quick tool education stakeholders can use to determine the most appropriate channels to deliver remote learning for different populations. It is remarkable that, regardless of the availability of computers and online platforms, it is recommended the additional support of paper-based response ('takehome packages') and communication between teachers and parents by SMS, or phone.

The article does not offer the global perspective about distance learning we can have after COVID-19 because it is based on 15 previous studies published from 2004 to 2015 and identified by using the key search-terms: 'teacher professional development' or 'teacher training' combined with 'online learning/teaching', 'blended learning/teaching', and 'e-learning/teaching'. The beauty and flexibility of the proposal lies in it being a metaaggregative approach so it can be enhanced with new experiences, without reinterpreting the original findings, as far as new data is supported by unequivocal or credible evidence. Accordingly, a wider outlook, without changing the original conclusions, could be accomplished by amplifying the findings - inclusion of some international cases and examples in the use of frugal technologies by teachers during lockdown - and deriving if new components are to be aggregated for TPD strategies. 
Apart from that, the comprehensive framework of components of TPD for OBL depicted by the authors is appropriated for decision making all around the world. Moreover, a formal starting point for organising and planning TPD in the shift to digital is so convenient at this time, when COVID-19 has made us rethink the role of distance learning in education.

From an international perspective, one of the components the authors identified should be underlined: "(2) Acknowledgement of the existing context regarding OBL". They state these aspects must be taken into account: institutional and personal planning to avoid stress, institutional characteristics (context and culture), possible existing programs (cost reduction and better sustainability) and the financial component. It is clear that these aspects differ greatly from one country to another and they should be acknowledged when trying to import TPD strategies that succeeded elsewhere. Anyway, COVID-19 has shown us something about changing contexts. On one hand, a very concrete local TPD strategy could tackle the specific socio-economic situation, cultural background and limitation of resources of the region. On the other hand, education systems need a 'Plan B' for safe and effective learning delivery when schools are unexpectedly closed; we yearn for resilient systems with resources and redundancies that can be leveraged in times of shock when core delivery models are disrupted (Dreesen et al., 2020).

Another example of context-related handicap is the additional problem that has been identified (Mayer-Crittenden, 2020) in those countries or regions where language immersion is the method of instruction. Wherever the regular school curriculum is taught in a target language, which is not used at home, students are less-frequently exposed to the language being learnt than they used to. As research has shown (Thordardottir, 2011), that exposure is vital for maintaining their skills, therefore preservation tasks have had to be scheduled, as well as reinforcement activities in back-to-school programs. TPD should take this into account in these situations.

United Nations (2020) encourage a human-centred approach to the crisis and its recovery which aligns with TPD in general and in particular with the importance that the authors give to peer support as a main category in the fifth component. A close-knit community of teachers supports its members thanks to peer interactions and discussion, work sharing, peer collaboration, peer feedback and peer assessment. The article points out how teachers gain confidence and motivation when they feel part of a network. International networks are the next level to local networks and a lot can be done by institutions regarding this issue. Enlight (https://enlight-eu.org/) is an example of an institutionally powered international network where the exchange of educational materials allows to formulate accessible solutions and enhance the educational offer for students. It is expected to establish the foundations of an integrated European University System.

Despite the relevance of always being aware of a local perspective, education systems and educators are facing (and will have to deal with) global challenges. The future of learning requires carefully generating the new roles teachers must play in OBL and an international perspective in both TPD and Faculties of Education will help to build resilient education systems for the long term. Future research on TPD for OBL could pay attention to some fields that have become relevant from an international perspective considering the COVID19 crisis: reuse of digital resources (OER, OCW, MOOCs) crafted by colleges from other countries; nature of digital assignments (public, multi-voiced, use of global resources); programming/reuse of bots to attend diversity; use of learning analytics for early detection of poor performance of students and openness for a resilient response to the closure of schools. 
Funding Funding for this work was provided by the University of the Basque Country (GIU 19/010, PPGI19/11) and by the Basque Government (IT1195-19).

\section{References}

Dreesen, T., Akseer, S., Brossard, M., Dewan, P., Giraldo, JP., Kameii, A., Mizunoya, S., \& Santiago, J. (2020). Promising practices for equitable remote learning; Emerging lessons from COVID-19 education responses in 127 countries. UNICEF Office of Research - Innocenti Research Brief 2020-10. https ://www.unicef-irc.org/publications/pdf/IRB\%202020-10\%20CL.pdf

Mayer-Crittenden, C. (2020). How to preserve French language learning during coronavirus school closures. The Conversation. https://theconversation.com/how-to-preserve-french-language-learning-durin g-coronavirus-school-closures-139179

Thordardottir, E. (2011). The relationship between bilingual exposure and vocabulary development. International Journal of Bilingualism, 15(4), 426-445.

UNESCO. (2020a). COVID-19 educational disruption and response. https://en.unesco.org/covid19/educa tionresponse

UNESCO. (2020b, April). Startling digital divides in distance learning emerge. https://en.unesco.org/news/ startling-digital-divides-distance-learning-emerge

UNESCO. (2020c, June). National learning platforms and tools. https://en.unesco.org/covid19/educationr esponse/nationalresponses

UNESCO \& ILO. (2020). Supporting teachers in back-to-school efforts. Guidance for policy-makers. International task force on teachers for education 2030. https://en.unesco.org/publications/supporting-teach ers-back-school-efforts-guidance-policy-makers

UNICEF. (2020). Remote learning COVID-19 response decision tree. https://inee.org/system/files/resou rces/UNICEF_COVID19_DECISION_TREE_V8_CLICK_HERE.pdf

United Nations. (2020). Policy brief: the world of work and COVID-19. https://unsdg.un.org/resources/polic y-brief-world-work-and-covid-19

Publisher's Note Springer Nature remains neutral with regard to jurisdictional claims in published maps and institutional affiliations.

Javier Portillo Doctor in Telecommunications Engineer from the University of the Basque Country. Former member of the Department of Systems and Automation Engineering of the School of Engineering of Bilbao. Currently in the Department of Didactics and School Organization of the Faculty of Education. His research activities include the areas of PLE, PLN and Learning Analytics.

Arantzazu Lopez de la Serna Doctor in Technology, Learning and Education from the University of the Basque Country. Degree in Pedagogy from the University of Deusto. Diploma in Teaching from the University of Mondragon. Title of Therapist by the EVTF (Basque School of Family Therapy). Her research activity includes the areas of Women, Technology, Educational Innovation, elearning, School Organization and prevention in education. 